\title{
Risk preferences as determinants of soil conservation decisions in Ethiopia
}

\author{
H. Teklewold and G. Köhlin
}

\begin{abstract}
Soil degradation is one of the most serious environmental problems in the highlands of Ethiopia. The prevalence of traditional agricultural land use and the absence of appropriate resource management often result in the degradation of natural soil fertility. This has important implications for soil productivity, household food security, and poverty. Given the extreme vulnerability of farmers in this area, we hypothesized that farmers' risk preferences might affect the sustainability of resource use. This study presents experimental results on the willingness of farmers to take risks and relates the subjective risk preferences to actual soil conservation decisions. The study looked at a random sample of 143 households with 597 farming plots. We found that a high degree of risk aversion significantly decreases the probability of adopting soil conservation. This implies that reducing farmers' risk exposure could promote soil conservation practices and thus more sustainable natural resource management. This might be achieved by improving tenure security, promoting access to extension services and education, and developing income-generating off-farm activities.
\end{abstract}

Key words: adoption-Ethiopia—risk preference—soil conservation

\begin{abstract}
The Ethiopian highlands cover $40 \%$ of Ethiopia's land mass but account for about $95 \%$ of all cultivated land. Almost $88 \%$ of its human population lives there, with $70 \%$ of the total livestock population of the country (Ayele 1999). It is estimated that over $90 \%$ of the economic activities in Ethiopia are concentrated in the highlands. The sustainable use of land in these areas faces problems due to continuous cropping and repeated cultivation of sloping lands without proper consideration for soil conservation and fertility amendments. The soil resources are eroding at an alarming rate, but at this time, there is insufficient awareness, both within and outside the farming community, of the sources of this problem. Now, even the more productive areas in Ethiopia are facing high rates of soil erosion.
\end{abstract}

Soil erosion-averaging $4.2 \mathrm{t} \mathrm{ha}^{-1} \mathrm{y}^{-1}(1.68$ tn $\mathrm{ac}^{-1} \mathrm{yr}^{-1}$ ) of soil loss-is a huge contributor to the low productivity of Ethiopian soils (Hurni 1993).As a result, soil erosion is putting out of use some 20,000 to 30,000 ha $(49,600$ to $74,400 \mathrm{ac}$ ) of croplands annually (Bewket 2007; FAO 1986). The Soil Conservation Research Project (Hurni 1993) estimated the effect of soil erosion on crop productiv- ity for the major crops using a production function based on time-series data. In this study, a loss of $1 \mathrm{~cm}$ of soil depth (about 100 $\mathrm{t} \mathrm{ha}^{-1}$ [40 th $\mathrm{ac}^{-1}$ ] of soil) was estimated to reduce about $2 \%$ and $4.5 \%$ of the production of wheat in vertisols (black, fissured soil) and red upland soil, respectively. Like in other subSaharan African countries (Sanchez et al 1996), depletion of the soil fertility of small Ethiopian farm plots is the fundamental biophysical limiting factor responsible for the declining per capita food production (Elias and Scoones 1999). In view of this, soil erosion and soil depletion constitute a national hazard, whose containment is a prerequisite for national development, particularly in a society that is agriculture based.

The traditional explanations for soil degradation relate to resource depletion and land mismanagement associated with limited soil conservation practices. Generally, the objectives of soil conservation are prevention of soil loss and management of soil fertility. Sheng (1989) defined soil conservation as a conscious process for the use and protection of land, including wise land use, necessary soil management, and erosion control. Some studies on the economics of soil conservation in developing countries have suggested incentives for farmers to adopt soil conservation by analyzing their household characteristics and the features and attributes of their farm operations (Thao 2001; Ervin and Ervin 1982; Saliba and Bromley 1986; Soule et al. 2000; Gebremedhin and Scott 2003). Generally, land tenure arrangements, soil characteristics, input and output prices, availability of off-farm employment, farm size, household size, discount rates, and government policies influence the use of (or refusal to use) soil conservation measures by farmers in developing countries.

Rarely, however, has the influence of risk aversion for adoption of soil conservation practices been addressed, and strong empirical evidence to test its importance and impact has been scarce and scattered. Feder et al. (1985), in their review of the conservation adoption literature, attributed this scarcity to difficulties in observing and measuring risk and uncertainty. Farmers are unlikely to invest in soil conservation unless they can see the benefits of soil erosion control. In practice, the major benefit that a farmer receives from soil conservation is the soil itself-a potential asset for future income. The stock of soil available to a farmer is essentially an economic asset that can be exploited through cultivation to yield a stream of present and future income (Barbier 1990). Often, the return for practicing soil conservation can be long in coming, a feature that helps explain low adoption rates (Shively 1997). However, delays in payback do not completely explain low rates of investment, even if subjective discount rates are high. In many cases, practical strategies to reduce soil erosion introduce economic risks that reduce their potential value. Although several empirical studies have shown that the assumptions of risk neutrality can overestimate the value of soil conservation (e.g., Ndiaye and Sofranko 1994), such assumptions remains pervasive in studies of soil conservation adoption and performance.

Considering the importance of risk, Binswanger et al. (1980) validated that a portion of the observed variation among

Hailemariam Teklewold is a PhD candidate, and Gunnar Köhlin is an associate professor and director of the Environment for Development Initiative in the Department of Economics at the University of Gothenburg, School of Business, Economics and Law, Gothenburg, Sweden. 
individual farmers' agricultural decisions can be related to variations in the same farmers' degrees of risk aversion (as measured in experiments), where the more risk averse choose more conservative options. Yesuf and Bluffstone (2009) also indicated that, in countries where poverty and environmental degradation are intertwined and credit and insurance markets are imperfect or completely absent, the critical factors affecting sustainability of resource use are the extent to which people discount the future and their willingness to undertake risky activities, such as investment decisions. Dillon and Scandizzo (1978) and Binswanger (1980) mentioned that poor people are risk averse and their production and investment decisions are characterized by a high degree of uncertainty and inefficiency, which in turn affects sustainable use of their resources.

Our study, therefore, was intended to measure the degree of risk preference of smallholder farmers and empirically examine the effects of farmers' risk preferences (plus other socioeconomic factors) on soil conservation decisions at the farm level. The importance of this study lies in identifying ways to enhance soil conservation practices and to assist policymakers in promoting appropriate soil conservation strategies. We test two main researchable hypotheses: that farmers with high-risk aversion behavior exist in the study area, and that the probability of farm households' soil conservation decision is negatively affected by a high degree of risk aversion. In addition, we expect that the choice of conservation system would be influenced by a number of factors, namely, farmers' attributes (level of education, farming experience, labor availability, wealth status, and social capital), farm characteristics (soil types, soil fertility, slope, plot size, and distance of plot from house), and policy-related variables (extension services, use of radio, market access, off-farm work, and land tenure security).

Economic Model for Soil Conservation. There are a range of approaches applied in the analysis of soil conservation, ranging from quantification of the national impacts of soil loss to the identification of factors that influence farmers' soil management decisions. The model used in this paper is an adaptation of Barbier's (1990) economic model of the soil-conservation investment decision of farmers in developing countries. The model posits price-taking producers who choose to install and maintain conservation practices in order to maximize the net present value of output. In our study, we extend the Barbier (1990) model to include farmers' risk preferences and other socioeconomic characteristics as factors influencing the adoption decision.

Let $f\left(x_{t}, s_{t}\right)$ be a vector of outputs produced at time $t$, with $x_{t}$ as a vector of production inputs used at time $t$, and $s_{t}$ as soil stock at time $t$. Consider a farm household that produces farm output in each period using a depletable input, $s$, and production inputs, $x_{t}$. Soil dynamics, $d s / d t$, is represented by the soil quality retained by the investment in soil conservation, $I\left(k_{t}, \theta_{t}, h_{t}\right)$, and loss of soil from inputs used in agricultural production, $x_{t}$. Investment in soil conservation, in turn, is a function of the stock of soil conservation structures $\left(k_{t}\right)$ and other factors, such as farmers' risk preferences $\left(\theta_{t}\right)$ and socioeconomic characteristics $\left(h_{t}\right)$. Let $p_{t}, w_{t}$, and $c_{t}$ be the respective price vectors corresponding to output, input, and soil conservation, respectively, at time $t$. The net present value of a stream of output is defined as the accumulated crop revenue minus the cost of production inputs and the cost of soil conservation investment discounted by the discount rate $(\delta)$. Thus, the farmer's objective function is to maximize the net present value of profit from agricultural production using the production inputs $\left(x_{t}\right)$ and soil conservation $\left(k_{t}\right)(\operatorname{Max}[x, k]$ II) (subscripts are suppressed), given by

$\underset{\{x, k\}}{\operatorname{Max}} \Pi-\int_{t=0}^{T} e^{-\delta t}[p f(x, s)-w x-c k] d t+e^{-\delta t} V\left(s_{t}\right)$,

and subject to

$d s / d t=I\left(k_{t}, \theta_{t}, h_{t}\right)-x$,

where $T$ is the last period, $d t$ is a mathematical expression indicating the change in time, and $V\left(s_{T}\right)$ is the scrap value of soil stock at the last period.

The first step in the optimization is the construction of the Hamiltonian $(H)$ in equation 3. The right-hand side of the equation of motion (equation 2) is multiplied by the costate variables $\lambda_{t}$ and is appended to the objective function from equation 1 :

$H=e^{-\delta t}[p f(x, s)-w x-c k]+\lambda[I(k, \theta, h)-x]$.

The costate variable $\lambda$ represents the shadow or implicit price of the equation of motion or the shadow price of the soil stock in time $t$.The amount of soil stock used (the right hand side of the motion equation [equation 2]) multiplied by the implicit price of the soil stock gives the shadow value of soil capital (or the dynamic cost to future generations using the soil). The optimal level of soil conservation investment can be determined by differentiating equation 3 with respect to $k$ :

$\frac{\partial H}{\partial k}=-e^{-\delta t_{C}}+\lambda\left[I_{k}(k, \theta, h)\right]=0$.

By rearranging equation 4 , the condition $\mathrm{e}^{-\delta t} c=\lambda\left[I_{k}(k, \theta, h)\right]$ implies that optimal soil conservation investment takes place at the level where the present value of the additional income derived from soil conservation equals the discounted additional cost of soil conservation. Alternatively, the optimal level of soil conservation can be determined as the level at which the additional user cost of soil erosion avoided just equals the discounted additional cost of soil conservation.

Soil is necessary for agricultural production, and yield increases with soil stock $(\partial f[s$, $x] / \partial s>0$ ), but yield also depends on other production factors. One of the features of this type of model is that stock of soil can be enhanced by investment in soil conservation $(\partial s / \partial I>0)$. In turn, risk aversion is related to soil stock through investment in soil conservation structures, implying that soil conservation investment decreases with the farmer's risk preferences $(\partial I / \partial \theta<0)$. The more risk-averse farmers may be reluctant to sacrifice short-term returns for less certain long-term benefits of conservation practices.

\section{Materials and Methods}

Econometric Approach: Analysis of Soil Conservation Decision. Most adoption studies treat the use of soil conservation measures as a discrete all-or-nothing adoption decision of a single practice. From a policy perspective, such studies do not supply information on how multiple practices can fit together into an overall conservation package. Adopting multiple soil conservation practices is common in Ethiopia because topography and soils frequently vary substantially within farms and because farmers usually diversify crop and livestock production. For a given plot of land, a farmer is assumed to have preferences over a discrete set of alternative soil conservation systems - a choice problem that requires application of multinomial discrete choice models. 
A multinomial logit model of a qualitative response variable characterizes a choice from discrete (nominal) alternatives by a decisionmaker as a function of attributes associated with each alternative, as well as the characteristics of the individual. Because of its analytical and computational tractability, this model has been applied extensively to discrete choice processes in economics with great success (Manski and McFadden 1981; Train 2003). A certain soil conservation system is chosen for a given plot, if and only if the expected utility from the selected option is greater than the utility obtainable from other available alternatives.

Consider the utility of farmer $n$ adopting soil conservation practice choice $j$ on the plot $U_{n j}$. The systematic component of the utility of alternative $j$ is specified as a function of an array of household $(H)$, farm $(F)$, and regional $(R)$ characteristics. Hence,

$U_{n j}=\alpha_{j} H_{n}+\Phi_{j} F_{n}+\varphi_{j} R_{n}+\varepsilon_{n j}$

where $\alpha_{j}$ is the parameters for household variables in the jth soil conservation alternatives, $\Phi_{j}$ is parameters for farm variables in the $\mathrm{jth}$ soil conservation alternatives, and $\varphi$ is parameters for regional variables in the $j$ th soil conservation alternatives.

Assuming the errors $\varepsilon_{n j}$ are independently and identically distributed with an extreme value distribution, the probability that alternative $j$ is chosen from $J$ alternative sets can be represented by the multinomial logit model function (McFadden 1974; Train 2003). The general form of the multinomial logit model is

$$
\text { Prob (choice }=j \mid J)=\frac{e \beta_{j} Z_{n j}}{\sum_{j} e \beta_{j} Z_{n j}}=\frac{\exp \left(\alpha_{j} H_{n}+\Phi_{j} F_{n}+\varphi_{j} R_{n}\right)}{\sum_{j} \exp \left(\alpha_{j} H_{n}+\Phi_{j} F_{n}+\varphi_{j} R_{n}\right)} \text {,(6) }
$$

where $j \mid J$ is the alternative $j$ from the $J$ alternative set, $\beta_{j}$ is set of parameters for the $j$ th alternative, $Z_{n j}$ is the variables for the $n$th observation at the $j$ th alternative, $n=1 \ldots N$ indexes the observation, and $j=1 \ldots J$ indexes the choices.

The dependent variable is $Y$, coded as 0,1 , 2 (alternative soil conservation systems); $Z_{n}$ is the explanatory vector (representing age, sex, education, extension contact, availability of family labor, risk attitude, time preference, plot size, soil type, slope, wealth and credit, etc). In order to identify unique coefficients for the alternatives, one of the outcomes in the multinomial logit model must be normalized to zero.

Even if the coefficient estimates have different interpretations depending on the omitted category, the probabilities remain the same. Alternatively, the coefficients can be used to calculate the partial changes in probabilities (marginal effect). The marginal effects measure the expected change in probability of the choice being made with respect to a unit change in an explanatory variable (Greene 2008). When there are $J=$ 3 number of soil conservation choices, the marginal change in probability of a given soil conservation system, given the change in continuous variable $Z_{n}$, is the partial derivative of $\operatorname{Prob}(Y=j)$ with respect to $Z_{n}$ :

$\frac{\partial \operatorname{Prob}(Y=j)}{\partial Z_{n}}=P_{j}\left[\beta_{n j}-\sum_{j=1}^{J-1} P_{j} \beta_{n j}\right]$,

where $P_{j}$ is the probability of selecting alternative $j$, and $\beta_{n j}$ is the parameter estimate of the of the variable for the $n$th farmers at the $j$ th alternative.

The marginal effect of a dummy variable on the event probability can always be accurately derived by taking the difference between the predicted probability when the variable is equal to 1 and when it is equal to zero:

$$
\begin{aligned}
& \Delta \operatorname{Prob}(Y=j)=\operatorname{Prob}\left(Y=j \mid Z, Z_{k}=Z_{1}\right)- \\
& \operatorname{Prob}\left(Y=j \mid Z, Z_{k}=Z_{0}\right),
\end{aligned}
$$

where $Z$ is the set of explanatory variables, $Z_{k}$ is the dummy variable, $Z_{1}$ represents when the dummy variable is one, $\left(Z_{k}=Z_{1}\right)$, and $Z_{0}$ represents when the dummy variable is zero, $\left(Z_{k}=Z_{0}\right)$.

Summing the marginal probabilities across the three soil conservation alternatives for a unit change of a given explanatory variable gives zero sums, implying that an increase in the adoption rate of the given choice due to a change in a particular characteristics' variable is compensated by a decrease in the adoption rate of other choices in the set.

Experimental Design: Risk Preference. The expected utility theory, developed by von Neumann and Morgenstern (N-M) in 1944 , is of central importance in describing decisionmaking under risk. Decision under uncertainty, as described by the N-M model, defines the utility to be maximized as the expectation of the utilities of the ran- dom alternatives. The concept of lottery as a formal device to represent risky alternatives is the basic building block for the N-M expected utility theory. A simple lottery is a list, $L=\left(P_{1}, \ldots, P_{N}\right) ; P_{N} \geq 0$ for all $n$; and $\Sigma_{n}$ $P_{n}=1$, where $P_{1}$ is the probability of the event occurring on the first outcome, $P_{N}$ is the probability of the event occurring on the last outcome, and $P$ is the probability of outcome $n$ occurring. The concept of "risk aversion" intuitively implies that, when facing choices with comparable returns, agents tend to choose the less risky alternative-a construction we owe largely to Friedman and Savage (1948). To put it differently, an agent is risk averse if replacing an uncertain final wealth by its expected value makes the agent better off.

In our study, which follows Binswanger's (1980) framework, the experimental method through predetermined choices approach was employed to elicit farmers' risk preferences by observing the reactions of farmers to a set of actual gambles in one period. In a real context, respondents were presented with certain realistic lotteries of the form $\left(q_{\max }, q_{\min }, P\right)$, promising a monetary prize for $q_{\max }$ (maximum payoff) with probability $P$, or $q_{\min }$ (minimum payoff) with probability $(1-P)$. The lotteries represent different real farming conditions and were designed with six different payoff levels, given a 50\% probability of bad or good harvesting conditions (table 1). Following the von N-M expected utility approach, an important ingredient is the specification of the utility function. The most popular parameter specification is the constant partial risk-aversion function, where the utility function is characterized by the risk-aversion parameter, $\theta$. Thus, a constant partial risk-aversion function as an approximation of $\left(U=[1-\theta] M^{1-\theta}\right)$ is used in order to measure and obtain a unique risk-aversion coefficient, where $U$ is the utility function, $\theta$ is the coefficient of risk aversion and $M$ is the certainty equivalent of the prospect. The upper and lower limits of $\theta$ are given in table 1.

The participants in the household survey were confronted with two experiments: one involved hypothetical trade-offs and the other the possibility of real payoffs. In the real payment experiment, the average payoffs for the household in the experiment was Ethiopian birr (ETB) 25 (\$1 [US] $=11.00$ ETB in 2008), which was approximately five times the daily wage level of the unskilled 


\section{Table 1}

Pay-offs and classifications of risk aversion associated with each option a farmer could choose.

\begin{tabular}{|c|c|c|c|c|c|c|c|}
\hline Choice & \multicolumn{2}{|c|}{ Payoffs (ETB)* } & $\begin{array}{l}\text { Expected } \\
\text { gain }(E)\end{array}$ & $\begin{array}{l}\text { Standard } \\
\text { deviation } \\
\text { (SD) }\end{array}$ & $\begin{array}{l}\text { Trade offs } \\
(Z) \dagger\end{array}$ & $\begin{array}{l}\text { Approximate } \\
\text { risk aversion } \\
\text { coefficients }(\theta)\end{array}$ & $\begin{array}{l}\text { Risk-aversion } \\
\text { category }\end{array}$ \\
\hline 5 & 9.00 & 18.00 & 13.50 & 4.50 & 0.71 to 0.78 & 7.47 to 1.74 & Severe \\
\hline 4 & 8.00 & 24.00 & 16.00 & 8.00 & 0.50 to 0.71 & 1.74 to 0.81 & Intermediate \\
\hline 1 & 0.00 & 40.00 & 20.00 & 20.00 & $-\infty$ to 0.00 & 0.00 to $-\infty$ & Neutral \\
\hline
\end{tabular}

laborers in the study area. Table 1 explains the basic structure of the experiment. The sample farmers were presented with a choice of six alternatives. Once the farmers selected one of the alternatives, they had a $50 \%$ probability of getting either the bad harvest or good harvest payoffs. The experiment consisted of offering farmers a set of alternatives where higher expected gain could only be obtained at the cost of higher variance-thus a decline in risk aversion.

Basically, individuals were assumed to be risk averse in cases where a certain outcome with a lower payoff was preferred over an uncertain outcome with a higher expected payoff. In contrast, risk-seeking behavior occurs when individuals consistently choose a gamble over a certain payoff with a higher payoff value. For instance, choice 1 is a safe alternative where subjects could earn ETB 10, with either a bad or good outcome. In alternative 5 , a coin was tossed, and the subject received ETB 2 if the coin showed heads and ETB 38 if the coin showed tails. Compared to choice 1, the individual's expected gain now increased by ETB 10, but if heads (bad outcome) turned up, it would reduce the return by ETB 8 . In the meantime, the standard deviation in gain increased from ETB 0 to ETB 18. Hence, with such uncertainty in gains, choice 5 involves more risk than the previous choices (choices 1 to 4).

Study Areas and Data. The data in this study were derived from a formal survey of a random sample of farm households, December 2003 to January 2004. The areas selected for this study, Ankober and BasonaWerena districts, are located within the North Shewa zone, in the Amhara Regional State of Ethiopia. North Shewa is a major agricultural region in the central highlands of Ethiopia, with a rugged, mountainous terrain where altitudes range from 1,600 to $3,500 \mathrm{~m}(5,249$ to $11,483 \mathrm{ft})$ above sea level. The area has two periods of rainfall, averaging 900 to $1,740 \mathrm{~mm}$ (35 to $68 \mathrm{in}$ ); the main rainy season (Meher) runs from July to September, and the short rainy season (Belg) is from January to April. The concentration of rain in heavy showers, coupled with an undulating landscape, causes significant erosion throughout the area.

A two-stage cluster sampling technique was employed to randomly select one village from each district and households from each village. The list of 29 villages in the Basona-Werena district and 18 villages in the Ankober district served as the sampling frame for the choice of the two villages, while households within each village were the sampling units. The sample households were randomly selected from the villages using lists that exhaustively record all members of the two villages.

A structured questionnaire was prepared, and the sampled respondents were interviewed. Initial presurvey tests were made in the selected villages to verify the feasibility of the study and allow redesign of the questionnaire if needed. In the randomly selected farm households, the head of the household was surveyed personally by experienced interviewers under close supervision by one of the authors. The enumerators also had special training to make sure they understood each question and the reason for the information captured in the survey. The respondents were interviewed in their local language, Amharic. As a result of the careful preparations, there were no rejections of the central questions in the survey by the respondents, and we are confident that the data is of unusually high quality. Information was also gathered in discussions with other key actors (e.g., field extension agents and soil conservation experts).

The survey included a total of 143 farm households, with 597 farming plots, and gathered information on the farmers' socioeconomic characteristics (such as age, household size, educational level, land-holding status, extension contact, availability of credit, availability of modern farm inputs, community participation, social organization, transportation cost, etc.) and farm characteristics (plot size, number of plots, soil fertility, slope of each plot, soil type, distance of plot from the house, cultivation arrangements, etc.). For identification purposes, the interviewers sketched all the plots farmed by the respondent and then collected detailed information for each plot, referring to the sketch as needed. The survey also elicited information from farmers regarding their risk preferences using the experiment mentioned above.

\section{Results and Discussion}

We found that indigenous soil conservation techniques were considered part of the farming system in the study areas. Indeed, in both areas, most farmers were familiar with traditional land improvement-conservation techniques, such as stone terraces and soil bunds. These are embankments of stone or soil constructed along the contour of the land to control the surface water runoff down the slope. The two soil conservation structures require different investments in amount of time and labor and have different effectiveness against erosion (Gebremedhin and Scott 2003). In the Basona-Werena and Ankober districts, about $27 \%$ and $38 \%$ of the plots, respectively, have stone terraces. However, no more than $16 \%$ to $18 \%$ of the plots in both areas use soil bunds. In Ankober, soil 
Table 2

Frequencies of farmers' responses to risk preferences corresponding to real and hypothetical experiements.

\begin{tabular}{|c|c|c|c|c|c|c|}
\hline \multirow[b]{2}{*}{$\begin{array}{l}\text { Risk-aversion } \\
\text { category }\end{array}$} & \multicolumn{2}{|c|}{ Basona-Werena } & \multicolumn{2}{|l|}{ Ankober } & \multicolumn{2}{|l|}{ All samples } \\
\hline & Farmers (\%) & $\begin{array}{l}\text { Cumulative } \\
\text { farmers (\%) }\end{array}$ & Farmers (\%) & $\begin{array}{l}\text { Cumulative } \\
\text { farmers (\%) }\end{array}$ & Farmers (\%) & $\begin{array}{l}\text { Cumulative } \\
\text { farmers (\%) }\end{array}$ \\
\hline \multicolumn{7}{|c|}{ Risk preferences in hypothetical experiment } \\
\hline Extreme & 29.6 & 29.6 & 35.7 & 35.7 & 32.6 & 32.6 \\
\hline Severe & 19.7 & 49.3 & 17.1 & 52.8 & 18.4 & 51.0 \\
\hline Intermediate & 25.4 & 74.7 & 7.1 & 59.9 & 16.3 & 67.3 \\
\hline Neutral & 7.0 & 100.0 & 11.4 & 100.0 & 9.2 & 100.0 \\
\hline \multicolumn{7}{|c|}{ Risk preferences in real experiment } \\
\hline Extreme & 31.0 & 31.0 & 32.9 & 32.9 & 31.9 & 31.9 \\
\hline Severe & 21.1 & 52.1 & 21.4 & 54.3 & 21.3 & 53.2 \\
\hline Intermediate & 21.1 & 73.2 & 8.6 & 63.1 & 14.9 & 68.1 \\
\hline
\end{tabular}

conservation structures have traditionally been constructed by the farmers themselves. A majority of the farmers in Ankober are aware of the need for a continuing increment of soil conservation practices and have perceived a subsequent decline in soil erosion. However, in Basona-Werena, the government has instead implemented a huge food-for-work program since the 1980s specifically to build soil conservation structures throughout the district.

Farmers' Risk Preference. The farmers' responses regarding risk preferences corresponding to the real and hypothetical experiments are presented in table 2. The results revealed that, in both the hypothetical and the real payoff experiments, a majority of farmers fell in the intermediate, severe, and extreme risk-aversion categories. In both experiments, $73 \%$ to $75 \%$ of the farmers in Basona-Werena and $60 \%$ to $63 \%$ of farmers in Ankober preferred the alternatives representing intermediate to extreme riskaversion. This result is slightly higher than Yesuf and Bluffstone (2009), who found that about $50 \%$ of farm households in the Ethiopian highlands chose the intermediate to extreme risk-aversion alternatives. The distribution of risk preferences in other similar studies in developing countries, such as Binswanger (1980) in India and Wik et al. (2004) in Zambia, is quite different than our result. About $83 \%$ of farmers in India and $52 \%$ of farmers in Zambia fell into the intermediate-to-moderate risk category, while only $32 \%$ of farmers in our study were in this group.
It is generally acknowledged that experiments conducted without real payment options may suffer from hypothetical bias. In order to avoid such a problem and provide enough incentive for the farmers to reveal their true preferences, our experiment included a real payoff. Comparison of the responses of the hypothetical and real experiments indicated that most of the respondents consistently maintained similar responses in both parts of the experiment. However, we saw a positive and significant correlation of responses in the risk aversion elicited with both hypothetical and real payoffs, contrary to what Wik et al. (2004) found.

Soil Conservation Decision. The major observed soil-conservation practices were stone terraces and soil bunds constructed by the farmers themselves. The decision to build soil conservation structures depends upon a wide variety of factors, many of which are specific to a particular area, household, or plot characteristic. The explanatory variables for this decision, included in our analysis are based on the theory discussed above and the literature on conservation investment. Expected effects of household, plot, and regional characteristics on choice of soil conservation practices are included in table 3 .

Attitude towards risk is a variable that measures farmers' willingness to take risks and is a potentially important determinant on the decision to use soil conservation practices. Risk aversion can have important implications for the adoption of technologies and the farmers' production-consumption plans. Various studies have shown that farmers plan their investment under risk (Binswanger 1980; Yesuf and Bluffstone 2009). The use of soil conservation, on the other hand, entails subjective risk (uncertainty of yield), particularly in the short term. In the longer term, the determining factor is whether soil conservation itself increased or reduced production risk.

Time preference is a variable that measures the extent to which a household is likely to postpone current consumption for future income or the extent to which households discount future benefits for current consumption. High subjective discount rates may be associated with extreme poverty, when immediate subsistence is uncertain. More fundamentally, a high discount rate decreases the net present value of future benefits from soil conservation. Thus, there is an expected inverse relationship between farmers' discount rate and a decision to invest in soil conservation.

An expected change of land holdings is used as proxy for land tenure insecurity. It represents a variable that indexes a household's attitude toward change in land size. Farmers may be insecure (perception of insecurity) about their current farms due to frequent redistribution of lands (Admassie 2000). Studies have also shown that tenure security is essential for adoption of soil conservation practices (Gebremedehin and Scott 2003). It is, therefore, expected that tenure insecurity (expected decline of land holdings) is negatively related to soil conservation adoption.

As information and communication mechanisms, contact with various sources of 
Table 3

Descriptive statistics for the multinomial logit model variables.

\begin{tabular}{|c|c|c|c|c|c|c|}
\hline Variable & Variable definition & Mean & $\begin{array}{l}\text { Standard } \\
\text { deviation }\end{array}$ & Minimum & Maximum & $\begin{array}{l}\text { Expected } \\
\text { effects }\end{array}$ \\
\hline \multicolumn{7}{|l|}{ Dependent variables } \\
\hline Stone terrace & Has stone terracing $(1=$ yes $)$ & 0.25 & - & 0.00 & 1.00 & \\
\hline Soil bund & Has soil bunds ( $1=$ yes $)$ & 0.13 & - & 0.00 & 1.00 & \\
\hline \multicolumn{7}{|c|}{ Household characteristics } \\
\hline Sex & Sex of household head ( $1=$ male $)$ & 0.91 & - & 0.00 & 1.00 & $+/-$ \\
\hline Labor & Labor force (man-equivalent) & 2.65 & 1.16 & 0.50 & 6.90 & + \\
\hline Extension & Contact extension agent $(1=$ yes $)$ & 0.46 & - & 0.00 & 1.00 & + \\
\hline Radio & Has a radio ( 1 = yes) & 0.10 & - & 0.00 & 1.00 & + \\
\hline Off-farm & Off-farm work ( 1 = yes) & 0.39 & - & 0.00 & 1.00 & $+/-$ \\
\hline Oxen ownership & Household owns oxen ( 1 = more than one ox) & 0.69 & - & 0.00 & 1.00 & + \\
\hline Time preference & Farmers' discount rate & 89.61 & 36.39 & 12.91 & 186.04 & - \\
\hline \multicolumn{7}{|l|}{ Plot characteristics } \\
\hline Parcel & Number of plots & 5.40 & 2.73 & 1.00 & 15.00 & - \\
\hline Plot size & Plot size, timad* per plot & 1.00 & 0.62 & 0.13 & 4.00 & - \\
\hline Tenure & Tenure arrangements ( 1 = owner operated) & 0.93 & - & 0.00 & 1.00 & + \\
\hline Highly fertile soil & Fertility of soil ( 1 = high fertile) & 0.23 & - & 0.00 & 1.00 & + \\
\hline Medium fertile soil & Fertility of soil ( 1 = medium fertile) & 0.33 & - & 0.00 & 1.00 & + \\
\hline Soil type & Soil type (1 = vertisol) & 0.50 & - & 0.00 & 1.00 & + \\
\hline Gentle slope & Plot has gentle slope ( 1 = gentle slope) & 0.27 & - & 0.00 & 1.00 & + \\
\hline Steep slope & Plot has steep slope (1 = steep slope) & 0.39 & - & 0.00 & 1.00 & + \\
\hline Idir & Idir membership (1 = yes) & 0.10 & - & 0.00 & 1.00 & + \\
\hline
\end{tabular}

information, advice from extension agents, and use of radio, are expected to positively influence adoption of soil conservation practices. Use of radio and extension activities may help farmers better understand the potential effects of soil erosion and benefits of soil conservation, as well as enhance their technical capacity to apply soil conservation technologies. The influence of off-farm work is indeterminate a priori. Income generated from off-farm work is expected to have a positive influence if it helps buffer the short-term variations in output due to soil conservation practices. In this case, the implication is that farmers with off-farm incomes are better risk takers, vis-à-vis using soil- conservation practices, than those without off-farm income. On the other hand, offfarm income may have a negative influence, if a farmer's off-farm employment opportunities cause labor shortages (from competition between agriculture and off-farm activities) that restrict the farmer's ability to build soil conservation structures.

The regional characteristics that we focused on were market access and social interactions in the community. Distance from the home to the nearest all-weather road was a proxy for market access (transport cost). Nearest roads were associated with low farm-input costs and high farm-output prices, as well as greater opportunities for income-earning activities, primarily sale of farm produce. Market access offers incentives for farmers to improve or maintain their land quality, and thus a positive effect is expected. Farmers who have the advantage of good market access (including demand for high-value crops) may find adopting soil conservation practices very attractive economically. Existence of good road networks also facilitates the availability of and exposure to information and communication, leading to a positive influence on adoption of soil conservation practices. We included a district dummy (one for Basona-Werena and zero for Ankober) in the model to control for village 
differences in knowledge, farming traditions, and physical characteristics, for example.

Social capital is characterized by norms, interactions, and reciprocity, leading to cooperation and information flows. It consists of discrete platforms organized and run by members of communities or groups for various purposes, notably to enhance confidence, pool resources, encourage savings, and extend credit. In addition to specialized functions, these networks act as forums for the exchange of experience and information about market behavior, the movement of goods and prices, development needs and priorities, among others. Hence, they can be used to promote development endeavors.

Two variables are proxies for social capital in this study. One, community participation, means the household is engaged in soil conservation activities organized by the farmers' association. In most cases, the farmers' association organized campaigns to reclaim and preserve the communal lands in the area. It is thus expected that the spillover effect of this variable on household adoption of soil conservation will be positive. Studies have indicated that, where public soil conservation activities take place in the same community, but not on the household's own land, farmers will be more likely to adopt soil conservation due to the experience effect of reducing real conservation investment costs and awareness of the effectiveness of conservation (Gebremedhin and Scott 2003).

The second variable for social capital uses membership in idir, the traditional form of social organization. In small holder agriculture, the problem of labor shortage might be solved, for example, through idir - a form of mutual cooperation imbued with a team spirit. In idir, information flows among members, and they have labor-sharing arrangements. The effect of idir on adoption of soil conservation is indeterminate a priori. If the members enter an agreement to share labor for conservation activities, idir will positively affect the decision to use soil conservation; otherwise, other social activities will deter adoption of soil conservation practice.

Regression Results. The chi-square test statistic for the estimated multinomial logit model is 276.95, with 52 degrees of freedom. The null hypothesis that the nonintercept coefficients are jointly zero is rejected at the 0.01 probability level. This means that the empirical multinomial logit model is highly significant in explaining the choice of soil conservation practice by farmers. We used the Huber-White-Sandwich estimator of variances, instead of the conventional maxi- mum likelihood variance estimator, in order to avoid the problem of heteroscedasticity In the analysis of plot-level data, correlated observations may occur due to repeated measurements of the same subjects. Clustering the data allows repeated observations, which are not independent within groups, although they must be independent across groups so that standard errors can be adjusted for clustering within farm households to allow for correlation within the group. The predictive power of the model is quite appealing. The choice of none, stone terraces, or soil bunds is correctly predicted for $81 \%, 60 \%$, and $53 \%$ of the sample, respectively. These results are also an indication that we have made a correct classification of soil conservation technologies for our analysis. Although there is some variation in the labor input and efficacy of other technologies applied, overall they are more similar to the "no" category than the soil and stone bunds.

As we hypothesized, the farmer's decision to build stone terraces is significantly affected by extension services, sex of the household head, expected declines in land holdings, risk aversion, discount rate, number of plots, tenure arrangement (if owner operated), slope of the plot (medium steepness), use of the plot (for cropping), community participation, and the district dummy. On the other hand, choosing soil bunds significantly depends on the sex of the household head, age of the household head, family labor force, participation in off-farm work, trend of land holdings (expected declines in land holdings), plot size, tenure arrangement (if plot is operated by the owner), soil type, steepness of the plot, use of the plot (for cropping), and the district dummy. Estimated changes in probabilities for the variables used in the regression are presented in table 4 .

The farmer's attitude towards risk has a negative effect on the choice of stone terraces or soil bunds. Because conservation practices are affected by several random variables that result in uncertainty in yields, planning for soil conservation involves decision making under risk. The farmer's risk preference is thus related to such decision-making scenarios. The highly significant marginal effect coefficient on "none" indicates that the farmer's risk aversion increases the likelihood of nonadoption of soil conservation practices. The risk-averse farmers who do not invest in soil conservation may assume uncertain yield variations, increasing the probability of no soil conservation by about three percentage points. The result of the marginal effect again implies that a $1 \%$ increase in farmers' risk aversion would significantly $(p<0.05)$ decrease the probability of choosing stone terraces by three percentage points.

Farmers' risk-aversion behavior has the same negative effect on choice of soil bunds, but is statistically nonsignificant. One reason for the significant negative effect of farmers' risk preference for stone terraces over soil bunds may be that construction of stone terraces requires more labor and a longer time to produce the expected higher return in yield than soil bunds. As a result, the more risk-averse farmers may be less interested in investing in stone terraces than soil bunds. Figure 1 depicts the change in predicted probabilities of household decisions about soil conservation (none, stone terraces, or soil bunds) due to changes in risk-aversion behavior. The figure clearly shows that as risk aversion increases, the probability of adoption of stone terraces continuously declines, no conservation increases, and use of soil bunds remains unchanged.

As expected, the farmers' time preference influences patterns of resource use in the current and future period. Farmers who have a higher discount rate are less inclined to long-term investments, giving more weight to the current, rather than the future, period. Our result confirmed the hypothesized relationship: the farmers' intertemporal discount rate negatively affected the decision to adopt soil conservation practices. A higher rate of time preference leads to the significantly higher $(p<0.05)$ likelihood of nonadoption of soil conservation. The marginal effect of nonadoption of soil conservation, due to a unit percentage change in the farmers' intertemporal discount rate, is about 0.2 percentage points. Even though the farmers' time preference negatively affects the use of both stone terraces and soil bunds, its effect is statistically different from zero $(p<0.05)$ on likelihood of adoption of stone terraces only. The result of the marginal effect indicates that a unit percentage increase in the farmers' intertemporal discount rate will decrease the probability of choosing stone terrace by about 0.2 percentage points. The two choices have different effects probably because (compared to soil bunds) farmers consider stone terraces to be more labor intensive. Their longer investment (time and labor) discourages the farmers' willingness to delay current consumption for future income.

The farmers' expectation that they will lose some of their land holdings significantly reduces the likelihood of choosing either stone terraces and soil bunds to a $10 \%$ and $5 \%$ significance level, respectively. Farmers 
Table 4

Marginal effects on probability of choice of soil conservation (stone terracing or soild bunds) or none.

\begin{tabular}{|c|c|c|c|}
\hline Variables & None & Stone terracing & Soil bunds \\
\hline \multicolumn{4}{|c|}{ Household characteristics } \\
\hline Sex & $-0.116(0.051) * *$ & $0.084(0.049)^{*}$ & $0.032(0.011)$ \\
\hline Age & $0.007(0.000)$ & $0.002(0.009)$ & $-0.008(0.003) * *$ \\
\hline Age-squared & $-0.0001(0.0001)$ & $0.0001(0.0001)$ & 0.0001 (0.0001) \\
\hline Literacy & $-0.022(0.047)$ & $0.013(0.042)$ & $0.009(0.014)$ \\
\hline Labor force & $0.011(0.019)$ & $-0.025(0.017)$ & $0.013(0.007)^{* *}$ \\
\hline Extension & $-0.062(0.054)$ & $0.079(0.049) * *$ & $-0.018(0.016)$ \\
\hline Radio & $-0.024(0.076)$ & $-0.014(0.058)$ & $0.037(0.041)$ \\
\hline Off-farm & $-0.105(0.064)^{*}$ & $0.069(0.055)^{*}$ & $0.035(0.021)^{* *}$ \\
\hline Oxen ownership & $-0.039(0.052)$ & $0.048(0.042)^{* *}$ & $-0.009(0.016)$ \\
\hline Income & $0.0001(0.0001)$ & $-0.0001(0.0001)$ & $-0.0001(0.0001)$ \\
\hline Land holding trends & $0.179(0.080)^{* *}$ & $-0.118(0.070)^{* *}$ & $-0.062(0.032)^{* *}$ \\
\hline Risk preference & $0.029(0.017)^{*}$ & $-0.029(0.015)^{* *}$ & $-0.0001(0.004)$ \\
\hline Time preference & $0.002(0.001)^{* *}$ & $-0.002(0.001)^{* *}$ & $-0.0002(0.0003)$ \\
\hline \multicolumn{4}{|l|}{ Plot characteristics } \\
\hline Parcel & $0.019(0.011)^{* *}$ & $-0.023(0.010) * * *$ & $0.003(0.003)$ \\
\hline Plot size & $-0.049(0.027)^{*}$ & $0.031(0.024)$ & $0.019(0.009)^{*}$ \\
\hline Tenure & $-0.120(0.040)^{* * *}$ & $0.092(0.038) *$ & $0.028(0.012)^{* *}$ \\
\hline Highly fertile soil & $-0.047(0.061)$ & $0.021(0.053)$ & $0.024(0.018)$ \\
\hline Medium fertile soil & $-0.009(0.042)$ & $-0.013(0.037)$ & $0.024(0.018)$ \\
\hline Soil type & $-0.002(0.038)$ & $0.040(0.032)$ & $-0.038(0.015)^{* * *}$ \\
\hline Gentle slope & $-0.178(0.064) * * *$ & $0.163(0.061) * * *$ & $0.016(0.018)$ \\
\hline Steep slope & $-0.208(0.060)^{* * *}$ & $0.164(0.056)^{* * *}$ & $0.044(0.020)^{* *}$ \\
\hline Plot distance & $0.001(0.001)$ & $-0.001(0.001)$ & $-0.001(0.001)$ \\
\hline Plot use & $-0.286(0.044) * * *$ & $0.241(0.038) * * *$ & $0.045(0.016)^{* * *}$ \\
\hline \multicolumn{4}{|c|}{ Regional characteristics } \\
\hline Road distance & $-0.007(0.017)$ & $0.013(0.016)$ & $-0.007(0.005)$ \\
\hline Community & $-0.163(0.037)^{\star *}$ & $0.152(0.029) * *$ & $0.011(0.020)$ \\
\hline Idir & $-0.056(0.105)$ & $0.056(0.095)$ & $0.001(0.032)$ \\
\hline District & $0.369(0.086) * * *$ & $-0.201(0.069) * * *$ & $-0.168(0.056)^{* * *}$ \\
\hline
\end{tabular}

Note: Numbers in parenthesis are standard error.

$\star p<.1 * \star p<.05 * \star * p<.01$

may be very cautious, given their tenure insecurity arising from land redistribution that may occur in response to growing population size and new membership in farmers' associations. The result of the marginal effect indicates that tenure insecurity significantly increases the likelihood of nonadoption of soil conservation by about 18 percentage points. Alternatively stated, this result implies that when farmers' security of land is not guaranteed (when farmers expect their land holdings to decline), the probability of using stone terraces or soil bunds is significantly reduced by 12 and 6 percentage points, respectively. This suggests that securing the tenure of a household's holding(s) should be an alternative policy option to encourage investments in soil conservation.
Access to extension services is another important variable, indicating that farmers can get information about better farming practices and enhance their understanding and technical capability for soil-conservation practices. The result of the marginal effect analysis indicates that access to extension services increases the probability of adopting stone terraces by about eight percentage points. The effect of this variable on the choice of soil bunds is negative, although statistically insignificant. It also suggests that the marginal effect of age on the likelihood of choosing soil bunds is negative and statistically different from zero at the $5 \%$ significance level. The probability of adopting soil bunds increases more for young farmers than old ones. The implication is that older house- hold heads probably have shorter planning horizons and are physically weaker, more resistant to change, and hence less interested in adopting soil conservation practices that have long-term effects. Thus, targeting young farmers for soil conservation intervention is probably an advisable strategy because they tend to be quicker and more flexible in deciding to adopt new ideas and technologies. With a longer life span-because these farmers are younger - they would anticipate a longer payout period for their investment.

Families are an important source of labor for farm operations and construction of soil conservation structures. This variable has a positive and statistically significant $(p<0.05)$ effect on the likelihood of adoption of soil bunds. The result of the marginal effect suggests that a unit increase in family labor size positively changes the adoption of soil bunds by about one percentage point. Its effect on the choice of stone terraces is negative and statistically insignificant. The marginal effect of off-farm work on the adoption of soil bunds is positive and statistically different from zero at the 10\% significance level, implying that the income obtained from offfarm work relaxes the liquidity constraints in conservation adoption. Participation in off-farm work increases the likelihood of adoption as evidenced by the negative and statistically significant marginal effect on the nonuse of conservation practices.

As hypothesized, the number of plots (fragmentation of farms) has a negative effect on adoption of soil conservation, indicated by the highly significant marginal effect on "none." One possible explanation is that with more plots, farmers may face increased transaction costs in constructing the conservation structures. Stone terraces, particularly, require the cumbersome activity of transporting stones to the different plots. This may significantly deter the adoption of stone terraces. However, the effect of the number of plots on the choice of soil bunds is positive but insignificant. The size of the fragmented plot area also positively influences the adoption of soil conservation practices. The significant marginal effect on "none" indicates that decreasing plot area increases the probability of nonadoption of soil conservation practices on a plot. This is probably because farmers may be constrained in building conservation structures because stone terraces and soil bunds are not suitable or convenient for a small plot. In addition, farmers assume that 
conservation structures take up space on a small plot and reduce the net cropping area. Unwillingness to invest on small plots could also be considered as an issue of economies of scale.

There is a significant difference between the two districts in terms of adopting soil conservation practices. Compared to BasonaWerena, farmers in Ankober have an increased likelihood of constructing stone terraces and soil bunds by about 20 and 10 percentage points, respectively. The adoption rate of soil conservation practice in Ankober is relatively higher (53\%) than in Basona-Werena (44\%). In Ankober, soil conservation and soil fertility maintenance dates back more than half a century. Personal communication and discussions with elderly people and experts from the local agricultural office revealed that construction of soil conservation structures is indigenous to the area with no government intervention so far. However, soil conservation in Basona-Werena only appeared some thirty years ago with massive government intervention. The longer and indigenous tradition of soil conservation in Ankober may be one reason for the relatively higher rate of adoption there. In addition, the topography of Ankober may also help promote soil conservation in the area. According to information from the district office of agriculture, the topography of both districts is mountainous, rugged, and plain landscape, respectively, covering $75 \%, 15 \%$, and $10 \%$ of Ankober and $50 \%, 27 \%$, and $23 \%$ of Basona-Werena.

\section{Summary and Conclusions}

This study uses survey data of smallholder farmers in the central highlands of Ethiopia to analyze the determinants of their choice of soil conservation practices. The study also endeavors to elicit farmers' attitudes toward risk preference using an experimental method. A link between risk aversion and resource protection in the form of soil conservation practice was found in this study. Results from the experimental method indicate that the estimated risk aversion is high, and the majority of the farmers were found to have intermediate, severe, or extreme risk aversion. Empirical results from the multinomial logit analysis demonstrate that a high degree of risk aversion has a negative effect on adoption of labor-intensive soil conservation practices. Farmer's risk aversion increases the likelihood of nonadoption of stone terraces and soil bund practices.

\section{Figure 1}

Risk aversion and adoption of soil conservation.

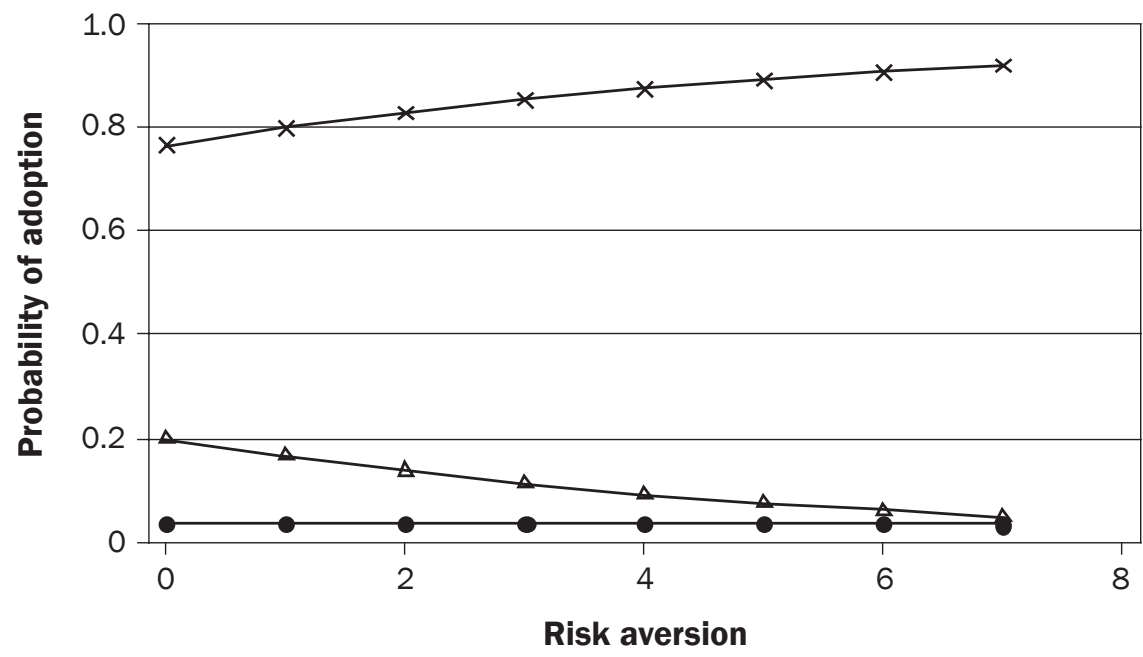

Legend

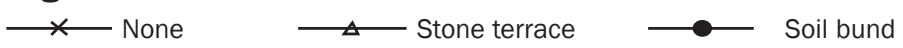

One implication of this work is that it is important to target the underlying reasons for nonadoption, such as high degrees of risk aversion and high subjective discount rates. Promotion of a longer-term and more effective soil conservation system (e.g., stone terraces) can not only be done through extension and programs targeting physical interventions, as indicated by the results from Basona-Werena where such activities have been common. Farmers in the study areas are poor with high estimated discount rates and levels of risk aversion. Because they are trapped in poverty, their high discount rates and risk preferences mean that they are still inclined to use erosion-prone practices to meet their present, urgent needs. The results imply that, to promote soil conservation, policies that reduce farmers' risk behavior should have priority, especially those that address land tenure security and rights, access to better education and extension services, and development of income-generating offfarm activities.

The results of this study are limited to the soil-conservation adoption decision. Because the observation is only whether a farmer uses a given practice or not, the study can only predict the effect of farmers' risk preferences and other factors on the probability that they will adopt a particular soil-conservation practice. The use of most of these soil conservation practices is considered to be a continuous investment, however. Moreover, the conservation effects of using soil-conserving practices are likely to vary according to the intensity to which they are used. Hence, it would also be important to study the extent to which such practices are used and what factors might influence the intensity of soil conservation practices.

\section{Acknowledgements}

The authors would like to thank participants of the 11th annual conference of the Agricultural Economics Society of Ethiopia in June 2008, Ethiopia and the 64th International conference of the Soil and Water Conservation Society in July 2009, USA. Financial and logistic support from the Ethiopian Institute of Agricultural Research and the Swedish International Development and Cooperation Agency is highly acknowledged. We are grateful to the four anonymous reviewers for their constructive and thorough reviews on the earlier version of the paper.

\section{Disclaimer}

The views expressed in this article are those of the authors and do not necessarily reflect the views of our financial and logistic supporters.

\section{References}

Admassie, Y. 2000. Twenty Years to Nowhere: Property Rights, Land Management, and Conservation in Ethiopia. Lawrenceville, NJ: Red Sea Press.

Ayele, G. 1999. Economic Analysis of Innovation and Adoption ofVertisol Technology: A Study of Smallholders' Mixed Farming in the Highlands of Ethiopia. PhD thesis, University of Hohenheim, Department of Agricultural 
Economics and Social Sciences in the Tropics and Subtropics, Stuttgart, Germany.

Barbier, E.B. 1990. The farm-level economics of soil conservation: The uplands of Java. Land Economics 66(2):199-211.

Bewket, W. 2007. Soil and water conservation intervention with conventional technologies in northwestern highlands of Ethiopia: Acceptance and adoption by farmers. Land Use Policy 24:404-416.

Gebremedehin, B., and M.S. Scott. 2003. Investment in soil conservation in northern Ethiopia: The role of land tenure security and public programs. Agricultural Economics 29:69-84.

Binswanger, H. 1980. Attitude towards risk: Experimental measurement in rural India. American Journal of Agricultural Economics 62:395-407.

Dillon, J., and P. Scandizzo. 1978. Risk attitudes of subsistence farmers in northeast Brazil: A sampling approach. American Journal of Agricultural Economics 60:425-35.

Elias, E., and I. Scoones. 1999. Perspective on soil fertility changes: A case study from southern Ethiopia. Land Degradation and Development 10(3):195-206.

Ervin, A.C., and E.D. Ervin. 1982. Factors affecting the use of soil conservation practices: Hypothesis, evidence, and implications. Land Economics 58:277-92.

Feder, G., R.E. Just, and D. Zilberman. 1985. Adoption of agricultural innovations in developing countries: A survey. Economic Development and Cultural Change 33:255-97.

Friedman, M., and L.P. Savage. 1948. The utility analysis of choices involving risk. Journal of Political Economy 56:279-304.

Green, W.H. 2008. Econometric Analysis. 6th ed. Pearson Prentice Hall.

FAO (Food and Agriculture Organization). 1986. Ethiopian Highlands Reclamation Study, Ethiopia. Final Report. Rome: Food and Agriculture Organization.

Hurni, H. 1993. Land degradation, famines, and resource scenarios in Ethiopia. In World Soil Erosion and Conservation, ed. D. Pimental, 27-62. Cambridge University Press.

McFadden, D. 1974. Conditional logit analysis of qualitative choice behavior. In Frontiers in Econometrics, ed. P. Zarembka, 105-142. New York: Academic Press.

Manski, C.F., and D. McFadden. 1981. Alternative estimators and sample designs for discrete choice analysis. In Structural Analysis of Discrete Data with Econometric Applications, ed. C.F. Manski and D. McFadden, 2-50. Cambridge, MA, USA: MIT Press.

Ndiaye, S., and A.J. Sofranko. 1994. Farmers' perceptions of resource problems and adoption of conservation practices in a densely populated area. Agriculture, Ecosystems and Environment 48(1):35-47.

Saliba, B.C., and D.W. Bromley. 1986. Soil management decisions: How should they be compared and what variables influence them. North Central Journal of Agricultural Economics 8(2):305-317.

Sanchez, P.A., A.M.. Izac, I. Valencia., and C. Pieri. 1996. Soil fertility replenishment in Africa: A concept note. In Achieving Greater Impact from Research Investments in Africa, ed. S.A. Breth, 200-207. Mexico City: Sasakawa Africa Association.

Shively, G. 1997. Consumption risk, farm characteristics, and soil conservation adoption among low-income farmers in the Philippines. Agricultural Economics 17:165-177.

Sheng, T. 1989. Soil Conservation for Small Farmers in the Humid Tropics. FAO Soils Bulletin, no. 60. Rome: Food and Agriculture Organization.

Soule, M.J., A. Tegene, and K.D. Wiebe. 2000. Land tenure and the adoption of conservation practices. American Journal of Agricultural Economics 82:993-1005.

Train, E.K. 2003. Discrete Choice Methods with Simulation. Cambridge University Press.

Thao, T.D. 2001. On-Site Costs and Benefits of Soil Conservation in the Mountainous Regions of Northern Vietnam. EEPSEA Research Report, no. 2001-RR13. Singapore: Economy and Environment Program for Southeast Asia.

Von Neumann, J., and O. Morgenstern. 1944. Theory of Games and Economic Behavior. Princeton, NJ, USA: Princeton University Press.

Wik, M., T.A. Kebede, B. Olvar, and S. Holden. 2004. On the measurement of risk aversion from experimental data. Applied Economics 36(21):2443-51.

Yesuf, M., and R.A. Bluffstone. 2009. Poverty, risk aversion and path dependence in low-income countries: Experimental evidence from Ethiopia. American Journal of Agricultural Economics 91:1022-1037. 